IZA DP No. 9402

Person Equivalent Headcount Measures of Poverty

Tony Castleman

James Foster

Stephen C. Smith

October 2015 


\title{
Person Equivalent Headcount Measures of Poverty
}

\author{
Tony Castleman \\ Catholic Relief Services and IIEP, George Washington University \\ James Foster \\ George Washington University \\ Stephen C. Smith \\ George Washington University and IZA
}

\section{Discussion Paper No. 9402 \\ October 2015}

\author{
IZA \\ P.O. Box 7240 \\ 53072 Bonn \\ Germany \\ Phone: +49-228-3894-0 \\ Fax: +49-228-3894-180 \\ E-mail: iza@iza.org
}

\begin{abstract}
Any opinions expressed here are those of the author(s) and not those of IZA. Research published in this series may include views on policy, but the institute itself takes no institutional policy positions. The IZA research network is committed to the IZA Guiding Principles of Research Integrity.

The Institute for the Study of Labor (IZA) in Bonn is a local and virtual international research center and a place of communication between science, politics and business. IZA is an independent nonprofit organization supported by Deutsche Post Foundation. The center is associated with the University of Bonn and offers a stimulating research environment through its international network, workshops and conferences, data service, project support, research visits and doctoral program. IZA engages in (i) original and internationally competitive research in all fields of labor economics, (ii) development of policy concepts, and (iii) dissemination of research results and concepts to the interested public.
\end{abstract}

IZA Discussion Papers often represent preliminary work and are circulated to encourage discussion. Citation of such a paper should account for its provisional character. A revised version may be available directly from the author. 


\section{ABSTRACT}

\section{Person Equivalent Headcount Measures of Poverty}

Headcount measures of poverty are by far the most common tools for evaluating poverty and gauging progress in global development goals. The headcount ratio, or the prevalence of poverty, and the headcount, or the number of the poor, both convey tangible information about poverty. But both ignore the depth of poverty, so they arguably present distorted views of the spatial distribution of poverty as well as the extent of progress against poverty over time. Additionally, headcount measures can provide incentives for policymakers and NGOs to focus their efforts on the least poor, an observation well understood among policymakers themselves. While other poverty measures mitigate these problems by capturing the intensity as well as the prevalence of poverty, they are often not central to policy discourse because they are perceived to be too "unintuitive" to have traction. There is a need for poverty measures that go beyond traditional headcount measures, but retain their direct interpretation. This paper presents person equivalent (p. e.) headcount measures, which do just that. Our approach draws on the logic of full-time equivalent jobs, adult equivalent incomes, and other constructs in economics. An initial period is used to calibrate the average depth of poverty among the poor, which then becomes the "person equivalent" underlying the p. e. headcount and the p. e. headcount ratio. We illustrate our methods using $\$ 1.25$ a day poverty data from 78 countries as provided by the World Bank, and show how the new measures map out different pictures of poverty and progress than traditional headcount measures. Overall, the picture is one of a more rapid decline in global poverty, but with significant redistributions of its burden across regions and countries. For example, p. e. headcounts are much higher than traditional headcounts in Latin America and the Caribbean and Sub Saharan Africa; in South Asia and East Asia and the Pacific the reverse is true. In Kenya the traditional headcount rose by 8 million and the p. e. headcount rose by 11 million; in South Africa the p. e. headcount fell by more than the traditional headcount. We discuss properties of the new measures, outline some generalizations and conclude with recommendations for using this approach in development goals to track progress and direct policy.

JEL Classification: $\quad$ I32, O15, D63

Keywords: poverty measurement, headcount, poverty gap, FGT indices, development goals, inclusive growth, multidimensional poverty

Corresponding author:

Stephen C. Smith

Department of Economics

Monroe Hall 306 (2115 G St. NW)

George Washington University

Washington, D.C. 20052

USA

E-mail: ssmith@gwu.edu

\footnotetext{
* The authors are grateful to the William and Flora Hewlett Foundation for research support through Grant \#2013-8857 to the George Washington University; and to the Institute for International Economic Policy for additional research support. We thank Steve Radelet for discussions and encouragement, and Misato Sato and Sam Gosney for excellent research assistance. We also thank participants of the GWU Symposium on the Economics of Ultrapoverty, the IEA-World Bank Round Table in Jordan, and seminars at GWU and Brookings.
} 


\section{Introduction}

The most common tools for monitoring poverty are headcount measures, which evaluate a country's poverty level using the number or prevalence of poor persons in the country. Yet as emphasized by Sen (1976), headcount measures have serious limitations stemming from their inability to differentiate among the poor. ${ }^{1}$ Large changes in poor incomes are ignored when the incomes stay below the poverty line, while small changes near the line can disproportionately affect measured poverty. Alternative poverty measures have been developed that address this problem by accounting for the intensity of poverty; but these measures are typically absent from policy discussions as they can be viewed as challenging for policymakers to explain intuitively, or for the public to understand.

The exclusive use of headcount measures to evaluate poverty can have significant implications for policies used to address poverty. Bourguignon and Fields (1990) demonstrated how using headcount measures encourages policymakers to ignore the poorest of the poor and focus on those with incomes just below the poverty line. Sen (1992, p. 105) contends that any government focusing solely on headcount measures "faces a strong temptation to concentrate on the richest among the poor, since this is the way that the number of the poor ... can be most easily reduced." A similar statement could be made for development NGOs, international organizations, or other aid partners whose efforts are judged using poverty headcounts. ${ }^{2}$

There is clearly a need for poverty measures that have a straightforward interpretation analogous to the headcount measures and yet appropriately reflect the intensity of poverty among the poor. This paper presents a new variety of poverty measures - called person equivalent headcount measures - to address this need. The average depth of poverty among the poor is calculated from an initial population; this benchmark "person equivalent" is used to translate between income and persons. Poverty is measured in "people space" by counting the number of person equivalents. The idea has analogies with the notion of a full time

\footnotetext{
1Sen (1976, p. 219) critique begins with the observation that headcount measures ignore the poverty depth: "An unchanged number of people below the 'poverty line' may go with a sharp rise in the extent of the short-fall of income from the poverty line." He also attacks headcount measures for ignoring the distribution of income among the poor.

${ }^{2}$ In a 2012 presentation, Steve Radelet, former Chief Economist with USAID, urged the development community to look beyond headcount measures, which ignore progress that takes place below the poverty line (Risley, 2012). Our paper was written in response to his message and the real world examples he described in subsequent conversations.
} 
equivalent employee, which measures employment using a benchmark workweek to account for variations in the hours worked by different employees. ${ }^{3}$

We present two measures. The first, called the person equivalent headcount, is analogous to the headcount, or the number of poor, but instead of counting persons, it counts person equivalents. The second, called the person equivalent headcount ratio, divides through by the overall population size; it is analogous to the traditional headcount ratio, or the share of the population that is poor. Both are shown to be linked to traditional gap measures of poverty, and exhibit a number of useful properties, including two that traditional headcount measures lack: monotonicity (which requires poverty to rise if a poor person's income falls) and continuity (which requires the measure not to change abruptly with a small change in income). We note that raising the income of a minimally poor person above the poverty line will lower a person equivalent headcount by less than one; raising the income of a person from far below the poverty line to just below the poverty line will lower the person equivalent headcount by more than one. In addition, both measures are decomposable by subgroup and hence are subgroup consistent.

The new measures are related to gap measures, but differ in one key respect - their numerical values have meanings that are vivid and intuitive, as headcounts that control for the condition of the poor. Traditional headcount measures can be misleading when the conditions of the poor change dramatically. Person equivalent headcount measures benchmark the initial conditions of the poor, and then employ this standard as a measuring rod to count the number of standardized poor, or person equivalents. The picture of poverty is altered in appropriate ways: it raises the level of measured poverty when the conditions of the poor become worse; it lowers it when the average conditions are better. The extent of this alteration in practice can be captured with the elasticity of the person equivalent headcount ratio with respect to the traditional headcount ratio (or "depth elasticity").

We illustrate our methods using $\$ 1.25$ a day data from PovcalNet at the World Bank, which are based on household survey data. We select two data points for each of 78 countries, one from the 1990s and a second from the 2000s, and show how the picture of poverty is altered over space and time when p. e. headcount measures are used. Overall, the picture is one of a more rapid decline in global poverty, but with significant redistributions of its burden across regions and countries. The depth elasticities of individual countries measured are typically greater than 1.0, but with wide variation. ${ }^{4}$ We also illustrate how poverty levels change when the benchmark

${ }^{3}$ See also the related notions of adult equivalent incomes commonly used in distribution analysis, the equally distributed equivalent income of Atkinson (1970), or adult equivalent labor as in Basu and Pham's (1998) model of child labor. ${ }^{4}$ A caveat is that some of the countries that we could not include due to lack of data have been estimated otherwise to have high average poverty depth; these include Afghanistan, Congo, Guinea-Bissau, Eritrea, Haiti, Liberia, Sierra Leone, and 
population is altered, but other conclusions are not affected, including country comparisons, poverty growth rates, and depth elasticities. We conclude with a discussion of some potential topics for future research, such as applying the approach to the squared poverty gap and to the increasingly influential multidimensional poverty measures and using person equivalent headcount measures in development goals.

Section 2 begins with the basic definitions and notation used in the paper, while section 3 constructs the new measures and discusses their characteristics. The empirical examples are presented in section 4 . Section 5 provides concluding remarks and future extensions.

\section{Definitions and Notation}

The population size is denoted by a positive integer $n$, with persons represented as $i=1, \ldots, n$. The vector $x=\left(x_{1}, \ldots, x_{n}\right)$ denotes a distribution of income among the population, while a poverty line $z>0$ is used to identify when a person is poor, namely, when $x_{i}<z$. Let $g=\left(g_{1}, \ldots, g_{n}\right)$ be the vector of normalized gaps, where $g_{i}=\left(z-x_{i}\right) / z$ for any person $i$ who is poor while $g_{i}=0$ for nonpoor $i$. The normalized gap of a poor person expresses the shortfall $s_{i}=\left(z-x_{i}\right)$ from the poverty line as a share of the poverty line $z$. A poverty measure $P$ aggregates the information in $x$ given $z$ to obtain an overall level $P=P(x ; z)$ of poverty. A simple example is given by the poverty headcount $q=q(x ; z)$ or the number of poor people in $x$ given $z$, while the headcount ratio $H=q / n$ is the share of the population that is poor.

Headcount measures do not distinguish among the poor; they ignore the progress a poor person makes on the way to escaping poverty. In contrast, the poverty gap ratio $P_{1}=\mu\left(g_{1}, \ldots, g_{n}\right)$, which is the mean normalized gap in a population, clearly differentiates among the poor according to the depth of their poverty, and registers a decrease whenever a poor person's income rises. Notice that it can be written as $P_{1}=H I=H A / z$ where $H$ is the headcount ratio, $I$ is the income gap ratio or average normalized gap among the poor, and $A=z I$ is the average shortfall among the poor. ${ }^{5}$ In general, the FGT class of poverty measures can be defined for $\alpha \geq 0$ as $P_{\alpha}=\mu\left(g_{1}^{\alpha}, \ldots, g_{n}^{\alpha}\right)$, or the mean of the normalized gaps raised to the power $\alpha$. Clearly $P_{0}=H$ is the headcount ratio and $P_{1}$ is the poverty gap measure, while $P_{2}$ is the FGT

Zimbabwe. Several of the omitted countries have a history of violent conflict perhaps a reason for missing data, but also a likely cause of poverty.

${ }^{5}$ Note that $I$ (or $A$ ) is an indicator of the average intensity of poverty among the poor, but is not a good overall measure of poverty. In particular, it can increase when a poor person escapes poverty and the remaining incomes are unchanged, thus violating a standard monotonicity requirement. 
squared gap poverty measure that is particularly sensitive to the poorest poor and accounts for inequality among the poor.

Each of these poverty measures is relative in that it evaluates the magnitude of poverty relative to the population size, and satisfies replication invariance, which requires a given distribution to have the same poverty level as one in which each income is replicated $k$ times. Other measures are absolute in that they satisfy linear replication, which requires a $k$-replication of a distribution to have $k$ times the poverty of the original distribution. The headcount $q$ is one example, and the total gap $T=q A$, or the total income necessary to raise all poor persons to the poverty line, is another. Both relative and absolute measures are helpful in evaluating income poverty across populations and their subgroups.

\section{Poverty Gaps and Person Equivalents}

Following Sen (1976), there has been a shift in the focus of poverty measurement from the identification step, by which the set of the poor are identified, to the aggregation step, by which the data are aggregated into an overall measure of poverty. Various improved aggregate measures have been proposed as replacements for the headcount $q$ (the number of the poor) or the headcount ratio $H$ (the share of the population that is poor). However, the simplicity of the headcount measures has continually led policymakers and applied researchers back to these crude measures. ${ }^{6}$ Even the poverty gap measure $P_{1}=H I$ which was critiqued by Sen, and popularized as part of the decomposable class of Foster, Greer, and Thorbecke (1984), is often dismissed as being too difficult for policymakers to grasp and use. Consequently, many discussions of poverty ignore significant variations in the intensity of poverty across space and time. With headcount measures, each poor person counts the same; with the poverty gap and related measures, the contribution of each poor person depends on the intensity of the poverty they experience.

In income poverty measurement, the simplest gauge of a poor person's intensity of poverty is the shortfall $s_{i}=z-x_{i}$ from the poverty line. The average depth or intensity of poverty among the poor can then be measured as $A$ or the average shortfall among the poor. Denote the average shortfall and the poverty headcount in an initial or benchmark distribution, $x^{0}$, by $A^{0}$ and $q^{0}$ respectively. We want to measure progress when changes occur and lead to a new distribution $x$ and its associated average intensity and headcount, $A$ and $q$. For simplicity, let us initially assume that there is no population growth, so that $n=n^{0}$. A traditional way of assessing progress is by using the change in headcounts, with $\Delta q=q-q^{0}<0$

${ }^{6}$ Foster and Sen (1997) discussed the tradeoff between the desirable properties of the new aggregate measures and the simplicity of the headcount measures and other "partial indices" of poverty that convey tangible information on one aspect of poverty. 
indicating an improvement in poverty, $\Delta q=q-q^{0}>0$ indicating a worsening, and $\Delta q=q-q^{0}=0$ suggesting that poverty is unchanged. This assessment might well be justified if the average intensity of poverty were held constant. However, if $A$ is also changing, and the depth of poverty is seen to be of relevance in assessing progress, then headcounts by themselves can provide a misleading view of poverty. For example, if incomes of all extremely poor persons in society rose to close to, but just below the poverty line, this would be viewed using $q$ as no progress at all. Likewise, if one person who is marginally poor (i.e., having an income just below the poverty line) became nonpoor and in the process all other poor persons become extremely poor, this would be seen as an unambiguous improvement by $q$. However, such a conclusion would be challenged if $A$ were taken into account. We consider an alternative way of measuring headcounts that controls for the changes in the average intensity of poverty.

To this end, we observe that the initial intensity $A^{0}$ can be used as a measuring rod in interpreting poverty comparisons and evaluating progress. For example suppose that the poverty line $z$ is the traditional $\$ 1.25$ a day, and that initially there are $q^{0}=$ 1000 poor persons with an average shortfall of $A^{0}=50$, so that the total shortfall in the population is $A^{0} q^{0}=\$ 500$. In the following period suppose that $q$ is unchanged at 1000 while the average shortfall declines to $A=45 \$$, leading to a new total shortfall of $A q=\$ 450$. Although the total number of poor persons is unchanged, progress has clearly been made towards reducing poverty. We can measure this improvement by dividing the new total shortfall $A q=\$ 450$ by the original average shortfall $A^{0}=50 \$$ to obtain the person equivalent (p. e.) headcount $q_{e}=900$. In words, the person equivalent headcount $q_{e}$ is the number of poor persons with a benchmark average shortfall $A^{0}$ that it would take to aggregate up to the total shortfall of Aq. It measures the poverty gap in "people space" by using the average shortfall of poor persons as the unit of measurement.

The person equivalent headcount is the number $q_{e}$ that solves $A^{0} q_{e}=A q$ and, hence, the person equivalent headcount is defined as

$$
q_{e}=q \frac{A}{A^{0}} .
$$

Progress can be gauged using the p. e. headcount, with $\Delta q_{e}=q_{e}-q^{0}<0$ indicating an improvement in poverty, $\Delta q_{e}=q_{e}-q^{0}>0$ indicating a worsening of poverty, and $\Delta q_{e}=q_{e}-q^{0}=0$ indicating that poverty is unchanged. The above example has $\Delta q_{e}=900-1000=-100$, which suggests that there has been progress towards reducing poverty on the order of 100 person equivalents. In contrast, the traditional headcount would indicate no progress at all. Note that the ratio $A / A^{0}$ is a transformation factor that converts the conventional headcount $q$ into the person equivalent headcount $q_{e}$. It reinterprets the average gap using the measuring rod of the benchmark average gap. In our example, $A / A^{0}=45 \$ / 50 \$=9 / 10$, so that the new distribution with 1000 poor persons and an average gap of $45 \pitchfork$ is viewed as having $q_{e}=900$ person equivalents. 
This approach can be extended to the variable population size case to obtain a measure of poverty $q_{e}$ that is absolute or independent of the number of the nonpoor. When population size varies, though, it is more traditional to report the headcount ratio, or the prevalence of the poor as a share of the overall population. Let $H^{0}=$ $q^{0} / n^{0}$ denote the initial headcount ratio and $H=q / n$ denote the subsequent headcount ratio. The person equivalent headcount ratio is defined as $H_{e}=q_{e} / n$. In our previous example, suppose that the population size was initially $n^{0}=5000$ and dropped to $n=4500$. Then with $q^{0}=q=1000$, we would have $H^{0}=1 / 5$ and $H=$ $2 / 9$ so that poverty as measured by the headcount ratio has risen, or $\Delta H>0$. However, since $H_{e}=900 / 4500=1 / 5$, this means that the person equivalent headcount ratio is unchanged; the number of person equivalents in poverty declined at the same rate as the overall population. Note that $H_{e}$ is the value that solves $A^{0} n H_{e}=A n H$ and hence the person equivalent headcount ratio may be defined as

$$
H_{e}=H \frac{A}{A^{0}} .
$$

As before, $A / A^{0}$ is the transformation factor converting the headcount ratio $H$ into the p. e. headcount ratio $H_{e}$. In this example, $H=2 / 9$ and $A / A^{0}=9 / 10$, and so $H_{e}=$ $1 / 5$.

The above presentation has employed the average gap $A$ as a measure of intensity to gauge the conditions of the poor. An alternative to the average gap is the income gap ratio $I=A / z$, which expresses the average gap as a percentage of the poverty line, rather than in monetary units, and is the intensity measure behind the poverty gap ratio $P_{1}=H I$. What would change if the income gap ratio $I$ rather than the average (monetary) gap $A$ were used in the construction of the p. e. headcount and headcount ratio? It is easy to see that since $I / I^{0}=A / A^{0}$, the transformation factor would remain the same, and hence the resulting person equivalent measures

$$
q_{e}=q \frac{I}{I^{0}} \text { and } H_{e}=H \frac{I}{I^{0}} .
$$

are identical to those defined in (1) and (2). Intuitively speaking, the person equivalent compares the intensity in the later period to the benchmark intensity, and the ratio is the same whether the intensity is measured in monetary units or in poverty line units.

The poverty gap ratio $P_{1}=\mu\left(g_{1}, \ldots, g_{n}\right)$ combines $H$ and $I$ to obtain a measure that reflects both the prevalence and intensity of poverty. It is a second indicator used to measure progress toward the poverty goal of the MDGs and is readily available on the World Bank's PovcalNet website. When published data exist on $P_{1}, H$, and $n$, the person equivalent measures $q_{e}$ and $H_{e}$ can be easily derived as follows. First find the benchmark intensity level $I^{0}=P_{1}^{0} / H^{0}$. Then calculate the person equivalent measures as

$$
q_{e}=n P_{1} / I^{0} \text { and } H_{e}=P_{1} / I^{0}
$$


In other words the person equivalent headcount ratio is found by dividing the poverty gap measure $P_{1}$ by the base intensity level $I^{0}$, while the headcount further nets out the population size $n$.

The expression for $H_{e}$ in equation (4) makes it clear that given a fixed initial average intensity level $I^{0}$, the equivalent headcount ratio $H_{e}$ is proportionate to the poverty gap measure $P_{1}$. Thus $H_{e}$ is a poverty measure that evaluates distributions in the same way as $P_{1}$, but has an alternative interpretation as the number of person equivalents per capita. It shares the same properties as $P_{1}$, including symmetry, population replication, the focus axiom, monotonicity, continuity and decomposability. ${ }^{7}$ In contrast, the original headcount ratio $H$ does not satisfy monotonicity and continuity; it ignores all improvements in the conditions of the poor that do not result in a crossing of the poverty line, but registers a discrete change when a poor person does cross. For instance, if a program targeting the ultra-poor successfully lowered their income shortfalls by $90 \%$, it would be regarded by $H$ with indifference - the prevalence of poverty has simply not changed. The program's progress would be revealed if the p. e. headcount ratio $H_{e}$ were used. In an analogous fashion, equation (1) reveals that the person equivalent headcount $q_{e}$ is proportionate to the total income gap $T=q A$ and hence evaluates distributions in a similar way. The properties satisfied by $q_{e}$ (and $T$ ) include symmetry, linear replication, the focus axiom, monotonicity, continuity and additivity, all of which are satisfied by the headcount measure $q$ apart from monotonicity and continuity. ${ }^{8}$ The monotonicity axiom ensures that $q_{e}$ reflects the changes in the intensity of poverty even when $q$ is unchanged.

We have described two new measures of poverty - the person equivalent headcount measure $q_{e}$ and the person equivalent headcount ratio $H_{e}$ - that evaluate poverty in "people space" with the help of a transformation factor based on the average depth or intensity of poverty in a benchmark period. If average depth falls below benchmark, the person equivalent headcount measure will be lower than its respective traditional headcount measure; if average depth rises above benchmark, the person equivalent headcount measure will be higher. To recap, when a person who was poor in an initial period crosses the poverty line, the impact on a person equivalent headcount measure depends on the depth of the person's poverty in the prior period: If the initial income was slightly below the poverty line, it would have a small effect on a person equivalent headcount measure, while if the income was well below the poverty line, it would have a large effect.

In certain contexts, we might be mainly interested in evaluating the percentage change in poverty through time. To evaluate the inclusiveness (or pro-poorness) of

\footnotetext{
7 Precise definitions can be found in Foster and Sen (1997), Foster (2005) and Foster et al (2013).

${ }^{8}$ By linear replication it is meant that a replication of the distribution that results in a $k$-fold increase in population leads to a $k$-fold increase in measured poverty. Additivity is captured in (5) or (6) below.
} 
growth, for example, the rate of reduction in poverty can be divided by the growth rate in per capita income to derive the growth elasticity of poverty - a measure of how well the economy is converting income growth into poverty alleviation. The traditional growth elasticity uses the headcount ratio $H$; the person equivalent headcount ratio $H_{e}$ could also be used. A related statistic compares the growth elasticities of $H_{e}$ and $H$ (or equivalently, the growth rates of $H_{e}$ and $H$ ) to obtain the depth elasticity of poverty $\varepsilon=\% \Delta H_{e} / \% \Delta H$, which indicates how progress in the headcount measure is translating into progress in the person equivalent headcount measure. ${ }^{9}$

The above discussion applies to evaluations of progress over time for a given population. The analysis can be readily extended to comparisons between subgroups defined according to geographical location, demographic characteristic, or some other parameter. For example, person equivalent headcount measures for different countries can be constructed and compared using the global $\$ 1.25$ a day poverty standard using a benchmark intensity level drawn from world data. Alternatively, interest might be regional in scope, in which case p. e. headcount comparisons could be made across countries within the region using a regional benchmark. Both examples divide an overall distribution $x$ into subgroup distributions and evaluate subgroup poverty using a person equivalent headcount measure benchmarked for the overall population. For simplicity of notation, let us focus on the two-subgroup case where the distribution can be written as $x=(a, b)$ for subgroup distributions $a$ and $b$; the same logic would apply to the many subgroup case. The benchmark intensity $A^{0}$ is obtained from an initial distribution $x^{0}$ drawn from the same general population as $x$, but potentially at an earlier time period. The case $x^{0}=x$ corresponds to an analysis of poverty over space (i.e., across subgroups); the case where $x^{0}$ is drawn from an earlier time period leads to comparisons over space and time.

Let $q^{a}$ and $A^{a}$ be the headcount and average intensity levels for distribution $a$, and let $q^{b}$ and $A^{b}$ be the associated values for distribution $b$. By the additivity of the headcount measure $q$ we know that

$$
q=q^{a}+q^{b}
$$

or the overall headcount in $x$ is the sum of the respective headcounts in $a$ and $b$. Given the benchmark level of intensity $A^{0}$, define the person equivalent headcount for distributions $a$ and $b$ by $q_{e}^{a}=q^{a} A^{a} / A^{0}$ and $q_{e}^{b}=q^{b} A^{b} / A^{0}$. Since $q A=q^{a} A^{a}+$ $q^{b} A^{b}$, it immediately follows from dividing through by $A^{0}$ that

$$
q_{e}=q_{e}^{a}+q_{e}^{b}
$$

\footnotetext{
${ }^{9}$ It also indicates how well changes in $H$ predict changes in $H_{e}$. Note that the growth elasticity of $H_{e}$ (or equivalently, of $P_{1}$ ) is the product of the depth elasticity $\varepsilon$ and the traditional growth elasticity of $H$.
} 
so that the overall person equivalent headcount is the sum of the respective person equivalent headcounts in $a$ and $b$. As compared to the crude headcount $q$, the p. e. headcount $q_{e}=q A / A^{0}$ is higher or lower depending on whether the intensity in $x$ is, respectively, higher or lower than the benchmark level. Equation (6) then provides the breakdown of the person equivalent headcount across the subgroups.

If $x=x^{0}$, the overall person equivalent headcount in $x$ reduces to $q_{e}=q\left(\frac{A^{0}}{A^{0}}\right)=q$, the traditional headcount, so that $q_{e}$ from equation (6) is equal to $q$ from equation (5). The decomposition in (6) is an alternative poverty breakdown to (5) that accounts for the differential depth of poverty experienced by people in the two regions. Using person equivalent headcounts can be interpreted by imagining that there is a redistribution of the population of poor people across the subgroups, with the higher intensity subgroup gaining person equivalents and the lower intensity subgroup losing. If there are two periods, then equation (6) can also be applied to the second period using the base intensity level $A^{0}$ and comparing across time to obtain the changes in each subgroup and overall. It is easy to show that $\Delta q_{e}=\Delta q_{e}^{a}+$ $\Delta q_{e}^{b}$, so that the change in the overall p. e. headcount is the sum of the respective changes in p. e. headcounts for the two subgroups.

From equation (5), or by the decomposability property of the headcount ratio, it follows that

$$
H=\left(n^{a} / n\right) H^{a}+\left(n^{b} / n\right) H^{b}
$$

and so the overall headcount ratio is a population-share weighted average of the subgroup headcount ratios. An analogous argument using equation (6) or decomposability for $P_{1}$ yields

$$
H_{e}=\left(n^{a} / n\right) H_{e}^{a}+\left(n^{b} / n\right) H_{e}^{b}
$$

which is the decomposition formula for the person equivalent headcount ratio. If applied to the original distribution, $H_{e}$ becomes $H$ so that (8) provides an alternative breakdown of the headcount ratio accounting for the intensities of poverty in the two groups. Equation (8) can also be used over time to link progress in the person equivalent headcount ratio to progress at the subgroup level.

The interpretations of $q_{e}$ and $H_{e}$ depend centrally on the benchmark level of intensity, and hence the time and region from which it is drawn. The benchmark is an average value in a region (which could be a particular country, a collection of countries, or the world) at a given point in time. A poor person with smaller than average income gap will account for less than one person equivalent; a poor person with a larger than average gap will add more than one. If a subgroup contains many poor people who are deeply poor, and the regional benchmark is sufficiently small, the number of person equivalents in the subgroup could well exceed the subgroup 
population, leading to a p. e. headcount ratio beyond the usual bounds. ${ }^{10}$ Likewise, a region with a large number of poor persons just below the poverty line could record a much lower p. e. headcount than its traditional headcount, particularly if the regional benchmark is high. In any case, the subgroup levels stay in proportion with one another even as the benchmark changes.

The technology of person equivalent headcounts is well suited for formulating development goals and targets that go beyond crude headcount measures and have a natural starting time from which to benchmark. The decomposition formula would support multilevel analyses at different granularities, from the global level down to an individual household. The methods could be adapted to different purposes by altering the region used in benchmarking. For example, to monitor global progress, the average intensity across the globe in the starting period could be used as the benchmark. A regional development bank might be interested only in reporting progress in its target area and could use a benchmark from a geographic region such as sub-Saharan Africa. Moreover, a country could monitor its own progress using the initial countrywide average intensity as a benchmark. And, as noted above, even when the benchmark is varied to reflect the different purposes and scope of analyses, the results are quite consistent. The person equivalent headcount measures obtained using one benchmark are proportional to those obtained with another, preserving their relative magnitudes across space, and their growth rates across time. There is no possibility of misaligned incentives for the parties conducting the analyses at different levels.

For example, suppose that the initial average intensity is $I_{C}^{0}=0.50$ in a country, $I_{R}^{0}=0.75$ in the region, and $I_{W}^{0}=0.25$ in the world. If the country's poverty gap ratio were 0.12 in the initial period and 0.06 in a subsequent period, the person equivalent headcount ratios as reckoned using the country benchmark would initially be 0.24 and subsequently 0.12 . If instead the regional benchmark were used, then the person equivalent headcount ratios would be 0.16 and 0.08 , respectively, or $I_{C}^{0} / I_{R}^{0}=2 / 3$ times these values, while at the world benchmark, the values would be 0.48 and 0.24 , respectively, or $I_{C}^{0} / I_{W}^{0}=2$ times as large as the initial values. Note that the trends in poverty for a given country are consistent irrespective of which benchmark is employed. Moreover, if the goal were to lower the person equivalent headcount ratio by $50 \%$ of the initial value, all three levels would track progress consistently and would meet the goal at the same time. In this sense, the goal would be robust to the choice of benchmark. ${ }^{11}$

${ }^{10}$ In a similar fashion, the number of full time equivalent employees at a company can exceed the number of persons employed.

11 This would not be true if the goal were to lower person equivalent poverty to a particular absolute level (or indeed by an absolute amount), since absolute levels and changes depend on the benchmark. In this case it would crucial to specify the benchmark ahead of time. 


\section{An Illustration: Global Poverty}

The person equivalent approach to evaluating poverty is illustrated using poverty data published by the World Bank on PovcalNet, which in turn is based on underlying household survey data. ${ }^{12}$ In order to gauge progress over time, we restrict consideration to countries for which data exist for at least one year in an initial range of 1992-2000 and one year in the later range of 2005-2010. A total of 78 countries from six regions satisfy this criterion. We construct a "developing world" made up of these countries, and extract the $\$ 1.25$ a day figures to create country poverty data for two time periods. Decomposition formulas allow headcount ratios and the poverty gap ratios to be calculated for the developing world and for regions. We apply the formula $A^{0}=z P_{1}^{0} / H^{0}$ (or equivalently $I^{0}=$ $P_{1}^{0} / H^{0}$ ) to data from the initial period to derive the appropriate benchmark level, which in turn is used to produce person equivalent headcounts and person equivalent headcount ratios.

Table 1 reports the poverty statistics for our full 78-country sample over the two periods using the global benchmark level of $A^{0}=39.5 \$$ per day (or equivalently $I^{0}=0.316$ ). The global headcount $q$ dropped by 512 million persons during this period, and since the average income shortfall among the poor also declined by more than $4 \$$, to $A=35.2 \$$ per day, the drop in person equivalents was 625 million, 113 million more than the drop in headcount. The conventional headcount ratio fell $44 \%$ from $H^{0}=0.36$ to $H=0.20$ between the two periods, while the person equivalent headcount ratio decreased by $50 \%$ from $H_{e}^{0}=0.36$ to $H_{e}^{1}=0.18$, once again reflecting the decrease in average depth. The global depth elasticity was about 1.1 , indicating that for every one percent drop in the headcount ratio there was a $1.1 \%$ decline in the person equivalent headcount ratio.

Table 2 explores regional poverty levels and trends using the same global benchmark. ${ }^{13}$ Figures 1 and 2 depict the levels graphically using maps of the regions. The move to person equivalent headcounts from traditional headcounts results in increases in poverty rates in Sub-Saharan Africa (SSA) and Latin America and the Caribbean (LAC) and decreases in the other regions; this is true for both

\footnotetext{
12 PovCalNet was accessed July 2015 at http://iresearch.worldbank.org/PovcalNet/index.htm

13 Note that data from the Latin America and Caribbean countries in PovCalNet use income data, whereas all other countries (except Latvia) use consumption data. A few countries in LAC have both consumption and income data available from the same year. For these countries poverty rates are substantially higher using income data, and the differences are even greater for the poverty gap than they are for the conventional headcount. Given these differences between consumption and income data - which the person equivalent headcount measure highlights - comparisons between LAC and other regions should be interpreted with caution.
} 
periods. A comparison of South Asia (SA) and SSA is particularly informative. The poverty headcount in SA was initially 608 million, far higher than in SSA at 260 million, and SA continued to dominate SSA in the numbers of poor people by a wide margin of over 180 million in the second period, even as the headcount fell in SA and rose in SSA. However, when viewed through the lens of person equivalent headcounts, the initial levels of the two regions are seen to be much closer and, in the second period, SSA actually overtakes SA by more than 35 million person equivalents. Incorporating the depth of poverty paints a rather different picture of poverty and progress in the two regions than headcount alone.

Headcount ratios take into account the differential population sizes across countries and through time. The data for $H$ show strong declines for all regions, with the success story of East Asia and the Pacific (EAP) being represented by a sharply falling value of $H$ (from 0.38 to 0.11 ). Notice that the decline in the headcount ratio in LAC (from 0.09 to 0.05 ) is also impressive in percentage terms. Indeed, the data on person equivalent headcount ratios also show progress in $H_{e}$ for both regions; but differences in average intensity shift the values for EAP down and LAC up, with the result that both regions reach the same level of $H_{e}$ (namely, 0.07) in the second period. Returning to the case of SSA and SA, the initial values for $H$ are not dissimilar (at 0.59 and 0.50 , respectively). However, regional differences in intensity generate a wide divergence in the initial period's values of $H_{e}$ for SSA and SA $(0.81$ and 0.44 , respectively), while differences in progress accentuate this further so that the final period $H_{e}$ values are, respectively, 0.62 and 0.23 . Depth elasticities were greater than 1.0 in four regions (SSA, SA, ECA, and EAP), indicating faster reduction in $H_{e}$ than $H$. LAC had an elasticity of 0.97 , indicating similar rates of reduction in the two headcount measures. The Middle East and North Africa (MENA) had a depth elasticity of 0.7 . Apparently, the reduction in $H$ was accompanied by a rise in the depth of poverty, leading to a smaller improvement in the p. e. headcount ratio $H_{e}$ than in $H$.

Table 3 contains poverty statistics for eleven of the 78 countries using the same global benchmark as above. We examine how the levels of $H$ and $H_{e}$ in a country differ from one another and how this alters the rate at which poverty changes. Four of the countries (China, India, Egypt, and South Africa) follow the lead of the global figures, and the EAP and SA regions, by having smaller values for $H_{e}$ than $H$ in both periods; four other countries (Bolivia, Brazil, Kenya, and Mozambique) follow the LAC and SSA regions by having higher $H_{e}$ values in both periods, indicating that the average depth is greater than the benchmark levels for both periods. In the three remaining countries (Vietnam, Nepal, and Niger), the level of $H_{e}$ is higher than $H$ in the initial period and lower than $H$ in the second, indicating faster poverty reduction in these countries when depth of poverty is taken into account than when only the prevalence of poverty is measured. Indeed, all countries except for Brazil and Egypt exhibit a higher rate of change in $H_{e}$ than in $H$, and thus have depth elasticities that exceed 1.0. For example, Nepal's conventional headcount ratio declined $4.4 \%$ per year and its p. e. headcount ratio declined by $5.4 \%$ per year, leading to an elasticity of 1.2. Two countries, Kenya and Bolivia, saw poverty rise between the two periods; 
large increases in their headcount ratios were magnified even further by their elasticities of 1.5 and 2.3, respectively. A depth elasticity greater than one means that the average depth of poverty worsened in countries where the prevalence of poverty worsened and improved in countries where the prevalence of poverty improved. For Brazil and Egypt the picture is different. Brazil's conventional headcount ratio declined more quickly (3.7\% per year) than its p. e. headcount ratio (3.0\% per year) resulting in a depth elasticity of 0.8 ; Egypt's p. e. headcount ratio increased slightly $(0.7 \%$ per year $)$ while its conventional headcount ratio declined (2.5\% per year), yielding a case where the depth elasticity takes on a negative value of -0.3. Figure 3 graphs the conventional headcount and person equivalent headcount ratios for these countries in the 2005-2010 period, and Figure 4 graphs the annual rates of change for the two rations between the two periods.

Table 4 presents the second period data for countries in Sub-Saharan Africa using a contemporaneous regional benchmark of $A^{0}=50.0 \$$ per day (the average income shortfall in the 2005-2010 period in the SSA countries). Note the wide range in the person equivalent headcount ratios (from 0.06 to 1.2 ) as compared to the conventional headcount ratios (ranging from 0.14 to 0.88 ), suggesting that the intensity is higher than the regional average for some countries with high prevalence of poverty, and lower than average for some countries with low prevalence. Cameroon, Niger, and South Africa, for example have much lower p. e. headcounts than traditional headcounts, while Madagascar and Zambia have much higher p. e. headcounts. Note that the relative picture across SSA countries would be the same if a different benchmark were used, such as the regional benchmark computed from period one data or the global benchmark used above: $q_{e}$ and $H_{e}$ would simply be shifted proportionally to reflect the new standard.

Table 5 shows how an individual country, Niger, can use its own base year average income shortfall (61.7 \$ per day in 1994) to benchmark its progress in combating poverty. Between 1994 and 2007, the number of individuals in Niger earning less than $\$ 1.25$ per day dropped from 6.9 million to 6.0 million, a modest decline. The person equivalent headcount dropped from 6.9 million to 3.4 million during the same period, a very large decrease. The person equivalent headcount ratio decreased at an annualized rate of $-5.3 \%$ per year and, as discussed above, this percentage change would be the same regardless of whether the benchmark used is the country's average income shortfall, the region's, or the world's. However, for its own internal assessment, a country may focus on the locally benchmarked figures, while knowing the findings will be consistent with globally, regionally, or even arbitrarily benchmarked figures. 


\section{Conclusions}

In this paper we have presented person equivalent headcount measures, which like traditional headcount measures are evaluated in "people space"; but instead of counting poor persons, these measures count person equivalents, as benchmarked by the average depth of poverty in a given place and time. The resulting measures are intuitive to explain and easy to calculate, but at the same time satisfy monotonicity and are sensitive to the depth of poverty like the poverty gap measures to which they are related. By explicitly accounting for the conditions of the poor, they remove the incentive to focus on the least deprived segments of the poor. When an extremely poor person escapes poverty, this has a greater impact on the measures than when a marginally poor person crosses the poverty line. And if a poor person makes good progress towards escaping poverty, but has not yet crossed the poverty line, this is regarded by person equivalent headcount measures as a positive achievement rather than something to be ignored.

We then applied our new measures to $\$ 1.25$-a-day global poverty data to show how they paint a different picture of poverty and progress than conventional headcount measures. For example, person equivalent headcounts are much higher in SubSaharan Africa and in Latin America and the Caribbean than traditional headcounts, and lower in South Asia and East Asia and the Pacific. Interestingly, SSA joins the SA and EAP regions in registering faster percentage declines in person equivalent headcount ratios than in traditional headcount ratios, while in LAC the rates of decline in the two measures are quite similar. An analysis by country likewise provides new insights into country experiences, with larger countries like China, India, and Brazil closely matching their regional results and others like South Africa departing widely from their regional picture.

Most of the countries we examined have a depth elasticity - or the percentage change in p. e. headcount ratio over the percentage change in the traditional headcount ratio - that is greater than one. South Africa lowered its headcount ratio a great deal, but with a depth elasticity of $\varepsilon=1.6$, the performance in terms of person equivalents was even more impressive. Kenya had a similar depth elasticity of $\varepsilon=$ 1.5 , but since the headcount ratio rose, this indicated an even more dramatic increase in p. e. headcount ratio. Other countries like Brazil with $\varepsilon<1.0$ had their improvements in p. e. headcount measures muted as compared to headcount ratios. Two countries - Egypt and Mauritania - exhibited negative depth elasticities, but they also had very small changes in headcount (and p. e. headcount) ratios. We illustrated how the benchmark underlying person equivalent measures is altered by using different geographic areas, from a global to regional or even country level. Different benchmarks result in different values for a country's person equivalent headcount measures, but since countries are affected proportionally, rankings are consistent and growth rates are unchanged. This consistency makes the person 
equivalent headcount ratio especially appropriate for use in multilevel development goals. ${ }^{14}$

The person equivalent headcount measures provide an intuitive way of incorporating information on the depth of poverty, but some might contend that they move too far afield from traditional headcount measures. Indeed, if the condition of a person changed discontinuously as the poverty line is crossed, it could make sense to retain this feature in a measure of poverty. One approach could be to construct "hybrid" measures such as $q_{\lambda}=\lambda q+(1-\lambda) q_{e}$ or $H_{\lambda}=\lambda H+$ $(1-\lambda) H_{e}$ where $\lambda \epsilon(0,1)$ represents the extent one believes that the discontinuity (and hence $q$ or $H$ ) is important. ${ }^{15}$ Now poverty is evaluated not only by counting the poor or counting person equivalents, but through a compromise between the two perspectives. This practical approach, however, can reintroduce an incentive to focus on the minimally poor - at least in the simplified perfect information scenario of Bourguignon and Fields (1990). It would be interesting to see whether the hybrid measures can provide benefits in other more realistic environments, such as when information asymmetries (say, between policymakers and aid workers) play a significant role.

One possible critique of the presentation up to now is its exclusive focus on monetary poverty. As emphasized in the 2000 World Development Report of the World Bank, poverty goes beyond monetary resources: it depends centrally on other key dimensions that should also be included when identifying the poor and measuring poverty. Of course all of the above measurement technology will apply directly to any other (cardinal) single dimensional variable (e.g. schooling or nutrition), thus identifying persons who are deprived in that variable and measuring their levels of deprivation. ${ }^{16}$

However, it is now generally recognized that the multiple dimensions must be simultaneously observed in order to identify who is poor and to evaluate how much poverty they have. And this typically requires expanded data and a new measurement technology. Distributions are now matrices, the single poverty line becomes a vector of "deprivation cutoffs," and an overall measure is constructed by

\footnotetext{
${ }^{14}$ A multilevel development goal sets targets and evaluates outcomes for several levels of population aggregation.

15 Foster and Shorrocks $\left(1991\right.$, p. 699) derives the class $P_{\lambda}=\lambda H+(1-\lambda) P$ axiomatically where $P$ is a continuous, decomposable measure and $\lambda \epsilon[0,1]$. A similar form arises in the measurement of ultra-poverty. See Foster and Smith (2015).

${ }^{16}$ For example, the other major target of the first MDG is halving hunger. Hunger is generally expressed in terms of the fraction of the population projected to suffer from a below-minimum caloric intake. Yet surely people moving toward that minimum, even if not yet crossing it, also represents progress against hunger. The person equivalent approach could be a valuable complement to existing headcount metrics for international poverty goals.
} 
aggregating across dimensions for the persons identified as poor. Unlike the unidimensional case, identification is not a simple matter in the multidimensional context; indeed, most theoretical presentations do not provide a practical method for identifying the multidimensionally poor, but instead fall back on a "union" approach, equating poverty with being deprived in any dimension. Moreover, the indicators available for multidimensional poverty analysis are often ordinal, rendering many theoretical solutions to the identification and aggregation steps inapplicable. The multidimensional headcount ratio $H_{m}$ is one index that works well with ordinal data; however, both it and the multidimensional headcount $q_{m}=n H_{m}$ suffer from the flaws of their unidimensional cousins as highlighted in this paper.

The challenge, then, of multidimensional poverty measurement has been to solve the identification and aggregation steps in a way that is consistent with ordinal data, but goes beyond crude headcount measures. One methodology that does this is found in Alkire and Foster (2011). ${ }^{17}$ A person is deprived in a given dimension if the achievement level is below a deprivation cutoff for the dimension. Each deprivation has a "value" and a person is poor or not depending on the extent of the person's multiplicity of deprivations, as measured by the deprivation count or sum of these values (where the maximum sum of all values is fixed at $d$, the number of dimensions). For example, if each deprivation has the same value, then the deprivation count is the number of deprivations the person is experiencing at the same time. A person is poor if the deprivation count meets or exceeds a poverty cutoff set between 0 and $d$. A poor person's intensity of poverty is measured as the deprivation count divided by its maximum $d$. The average intensity, denoted $A_{m}$, is the sum of the intensities of the poor divided by their number $q$. The adjusted headcount ratio is then given by $M_{0}=H_{m} A_{m}$.

Note that the form of this measure is entirely analogous to that of the poverty gap ratio $P_{1}=H I$, which underlies the person equivalent headcount measures for monetary poverty. Could our technology be applied in the multidimensional case to transform the adjusted headcount ratio into a multidimensional person equivalent headcount ratio? If so, then it could offer helpful interpretations for the many applications of $M_{0}$ in common use, including official measures in several countries and the Multidimensional Poverty Index (MPI) published in the annual Human Development Report by the United Nations. ${ }^{18}$ This would be a useful direction to pursue in future work.

In addition, we could also consider monetary poverty measures that stress the conditions of the poorest poor and take into account inequality among the poor. The distribution sensitive measures of Sen (1976), Watts (1968) and Foster, Greer and Thorbecke (1984) all have this characteristic and, as noted by Bourguignon and Fields (1990), they provide a positive incentive for focusing on the poorest poor

17 See also Alkire, et al (2015).

18 See Alkire and Santos (2014). 
first. Would it be possible to construct person equivalent headcount measures for each that would appropriately reflect inequality?

Consider the case of the squared poverty gap $P_{2}$ of Foster, Greer and Thorbecke. As noted above, $P_{2}$ places greater weight on persons who are further below the poverty line by squaring the normalized gaps $g_{i}$ before averaging. Clearly, $P_{2}=H I_{2}$ where $H$ is the headcount ratio and $I_{2}$ is the average of $g_{i}^{2}$ among the poor (an alternative intensity measure that accounts for inequality among the poor). Letting $I_{2}^{0}$ be its benchmark level, we can define $H_{e}^{\prime}=P_{2} / I_{2}^{0}$ and $q_{e}^{\prime}=n H_{e}^{\prime}$ as the person equivalent measures associated with $P_{2}$. An associated "severity elasticity" could evaluate the elasticity of $H_{e}^{\prime}$ with respect to $H$, or $\% \Delta H_{e}^{\prime} / \% \Delta H$.

Preliminary results using PovcalNet data suggest how accounting for distribution sensitivity by using $\mathrm{P}_{2}$ influences the picture of global poverty. Global totals are virtually unchanged (see Table 6). However, the regional picture becomes even more pronounced, with $H_{e}^{\prime}$ and $q_{e}^{\prime}$ moving further in the directions taken by $H_{e}$ and $q_{e}$ (see Table 7). Now the EAP region begins with524M person equivalents and ends up with only 94 million. In contrast, SSA rose from around 455 million in the 1990s to 471 million in the $2000 \mathrm{~s}$ - almost twice the number of person equivalents in SA and five times the number in EAP. The severity p. e. headcount ratio $\left(\mathrm{He}_{\mathrm{e}}\right)^{19}$ for $\mathrm{LAC}$ of 0.11 is substantially higher than that of EAP (0.07). Applying the person equivalent approach to distribution sensitive measures of poverty is an interesting topic for future work.

We have emphasized the suitability of the person equivalent technology for defining and tracking multilevel development goals. We now conclude with a brief discussion of its relevance to the Millennium Development Goals (MDGs) and the post 2015 agenda. Recall that the main indicator for the poverty portion of Goal 1 of the MDGs has been the $\$ 1.25$ a day headcount ratio $H$. The poverty gap ratio $P_{1}$ is also listed as a complementary indicator, but for reasons of simplicity has largely been absent from all but the most technical discussions. For example, in its assessment of progress in the MDGs, the United Nations (2014) presents only headcounts or headcount ratios as indicators of success or failure in reaching poverty goals. The World Bank's (2010) assessment uses $P_{1}$, but only to help explain the why poorer countries might have low growth elasticities and slower progress in reducing $H$. We would argue that depth should be included into the mix, both when evaluating the initial distribution of poverty and in monitoring the progress of countries. The person equivalent technology provides a simple and intuitive way of doing just this.

Ending extreme monetary poverty - interpreted by the UN and World Bank as reducing the $\$ 1.25$ a day headcount ratio to no more than $3 \%$ of the population - has emerged from the post-2015 discussion as a possible poverty goal. Assuming that the global population will be 9 billion, this could translate to a headcount of 270 million left behind. If this goal were achieved and only 270 million people remained

${ }^{19}$ When comparing $\mathrm{H}_{\mathrm{e}}$ with $\mathrm{H}_{\mathrm{e}}$, for clarity we refer to the former as the depth p.e. headcount ratio, and the latter as the severity p. e. headcount ratio. 
below the $\$ 1.25$ per day poverty line, it stands to reason that this group could contain some of the most deeply deprived, difficult-to-reach persons on earth. There is nothing in the goal that would prevent them from having an average depth of poverty that is twice the average depth of poverty among the poor in 2015 . Using the 2015 average depth as the benchmark, this would mean a person equivalent headcount of over a half a billion. Should this really be seen as an end to extreme poverty? Restating the goal in terms of person equivalent headcount ratios removes the ambiguity about the conditions of those left behind. Monitoring progress with this measure ensures that the depth of poverty is also being evaluated through time. Assessing initial conditions using person equivalent headcount measures presents a more complete guide to the challenges that lie ahead. 


\section{References}

Alkire, S., Foster, J., Santos, M., Seth, S., Ballon, P., and Roche, J., (2015)

Multidimensional Poverty Measurement and Analysis. Forthcoming, Oxford University Press.

Alkire, S., and Foster, J. (2011). 'Counting and Multidimensional Poverty Measurement.' Journal of Public Economics, 95(7-8): 476-487.

Alkire, S., and Santos, M. (2014). 'Measuring Acute Poverty in the Developing World: Robustness and Scope of the Multidimensional Poverty Index.' World Development, 59: 251-274.

Atkinson, A. (1970). 'On the Measurement of Inequality.' Journal of Economic Theory, 2: 244-263.

Basu, K., and Pham H. V. (1998). "The Economics of Child Labor." American Economic Review 88(2): 412-27.

Bourguignon, F., and Fields, G. (1990). 'Poverty Measures and Anti-Poverty Policy.' Recherches Economique de Louvain, 56(3-4), 409-427.

Foster, J., Greer, J., and Thorbecke, E. (1984). "A Class of Decomposable Poverty Measures". Econometrica. 3 52: 761-766.

Foster, J. (2005). 'Poverty Indices.' In Poverty, Inequality and Development: Essays in Honor of Erik Thorbecke (A. de Janvry and R. Kanbur, eds.). Kluwer Academic Publishers.

Foster, J., Lokshin, M., Sajaia, Z., and Seth, S. (2013) A Unified Approach to Measuring Poverty and Inequality: Theory and Practice. World Bank Press.

Foster, J.E., Sen, A.K., 1997. “On Economic Inequality. After a Quarter Century.” Annex to the enlarged edition of On Economic Inequality by Sen, A.K. Oxford: Clarendon Press.

Foster, J., and Smith, S. (2014) 'Measuring Ultrapoverty: A New Class of Indices and an Application to Rural Ethiopia Panel Data.' Unpublished.

Foster, J., and Shorrocks, A. (1991). 'Subgroup Consistent Poverty Indices.' Econometrica, 59(3): 687-709.

Risley, H. (2012). “The Economic Perspective: Causes and Constraints to Reaching the Ultra Poor" USAID Microlinks Blog, https://www.microlinks.org/blogs/economic-perspective-causes-andconstraints-reaching-ultra-poor 
Sen, A. (1976). 'Poverty: An Ordinal Approach to Measurement.' Econometrica, 44(2): 219-231.

Sen, A. K. (1992). Inequality Reexamined, Cambridge, MA: Harvard University Press.

United Nations, 2014 Millennium Development Goals Report, NY: United Nations, 2014.

Watts, H. W., (1968) "An Economic Definition of Poverty," in D. P. Moynihan (ed.). On Understanding Poverty, New York: Basic Books.

World Bank (2010). The MDGs after the Crisis: Global Monitoring Report 2010, Washington, DC: World Bank.

World Bank (2013). The State of the Poor: Where are the Poor and where are they Poorest?:

http://www.worldbank.org/content/dam/Worldbank/document/State_of_t he_poor_paper_April17.pdf 
Appendix: Countries and Years

\begin{tabular}{|c|c|c|c|c|c|}
\hline Cambodia & 1994 & 2009 & Paraguay & 1995 & 2010 \\
\hline China & 1996 & 2010 & Peru & 1997 & 2010 \\
\hline Indonesia & 1996 & 2010 & Uruguay* & 1995 & 2005 \\
\hline Lao PDR & 1997 & 2007 & Venezuela & 1995 & 2006 \\
\hline Philippines & 1994 & 2009 & Egypt Arab R & 1995 & 2008 \\
\hline Thailand & 1994 & 2010 & Iran Islamic $\mathrm{R}$ & 1994 & 2005 \\
\hline Vietnam & 1992 & 2008 & Jordan & 1997 & 2010 \\
\hline Albania & 1996 & 2008 & Morocco & 1998 & 2007 \\
\hline Armenia & 1998 & 2010 & Tunisia & 1995 & 2010 \\
\hline Azerbaijan & 1995 & 2008 & Yemen Rep & 1998 & 2005 \\
\hline Belarus & 2000 & 2010 & Bangladesh & 1995 & 2010 \\
\hline Croatia & 1998 & 2008 & India & 1993 & 2009 \\
\hline Georgia & 1996 & 2010 & Nepal & 1995 & 2010 \\
\hline Hungary & 1998 & 2007 & Pakistan & 1996 & 2007 \\
\hline Kazakhstan & 1996 & 2010 & Sri Lanka & 1995 & 2009 \\
\hline Kyrgyz Rep. & 1993 & 2010 & & & \\
\hline Latvia & 1996 & 2009 & Burkina Faso & 1994 & 2009 \\
\hline Lithuania & 1998 & 2008 & Burundi & 1992 & 2006 \\
\hline Macedonia & 2000 & 2008 & Cameroon & 1996 & 2007 \\
\hline Moldova Rep & 1997 & 2010 & Central Afr R & 1992 & 2008 \\
\hline Poland & 1996 & 2010 & Côte d'Ivoire & 1995 & 2008 \\
\hline Romania & 1998 & 2010 & Ethiopia & 1995 & 2010 \\
\hline Russian Fed & 1996 & 2006 & Ghana & 1998 & 2005 \\
\hline Tajikistan & 1999 & 2009 & Guinea & 1994 & 2007 \\
\hline Turkey & 1994 & 2010 & Kenya & 1994 & 2005 \\
\hline Ukraine & 1995 & 2010 & Madagascar & 1993 & 2010 \\
\hline Argentina* & 1995 & 2010 & Malawi & 1997 & 2010 \\
\hline Bolivia & 1993 & 2008 & Mali & 1994 & 2010 \\
\hline Brazil & 1995 & 2009 & Mauritania & 1995 & 2008 \\
\hline Chile & 1994 & 2009 & Mozambique & 1996 & 2007 \\
\hline Colombia & 1996 & 2010 & Niger & 1994 & 2007 \\
\hline Costa Rica & 1995 & 2009 & Nigeria & 1996 & 2009 \\
\hline Dominican R & 1996 & 2010 & Rwanda & 2000 & 2010 \\
\hline Ecuador & 1999 & 2010 & Senegal & 1994 & 2005 \\
\hline El Salvador & 1995 & 2009 & South Africa & 1995 & 2008 \\
\hline Guatemala & 1998 & 2006 & Swaziland & 1994 & 2009 \\
\hline Honduras & 1996 & 2008 & Tanzania & 1991 & 2007 \\
\hline Mexico & 1994 & 2010 & Uganda & 1996 & 2009 \\
\hline Nicaragua & 1993 & 2005 & Zambia & 1996 & 2010 \\
\hline Panama & 1995 & 2010 & & & \\
\hline
\end{tabular}

*Argentina and Uruguay data are urban only. 
Table 1: Person Equivalent Headcount Measures: Full Sample (1990s Global Benchmark)

\begin{tabular}{|c|c|c|c|c|c|c|c|c|c|}
\hline & $\begin{array}{c}\text { Range of } \\
\text { Years }\end{array}$ & $\begin{array}{l}\text { Population } \\
\text { n (millions) }\end{array}$ & $\begin{array}{l}\text { Headcount } \\
\text { q (millions) }\end{array}$ & $\begin{array}{l}\text { Headcount } \\
\text { ratio } H\end{array}$ & $\begin{array}{c}\text { Person-equivalent } \\
\text { headcount } \mathrm{q}_{\mathrm{e}} \text { (mill.) }\end{array}$ & $\begin{array}{c}\text { Person-equivalent } \\
\text { headcount ratio } H_{e}\end{array}$ & $\begin{array}{l}\text { \% change } \\
\text { in } \mathrm{H}\end{array}$ & $\begin{array}{c}\text { \% change } \\
\text { in } \mathrm{H}_{\mathrm{e}}\end{array}$ & $\begin{array}{c}\text { Depth } \\
\text { Elasticity }\end{array}$ \\
\hline World (78 & $1992-2000$ & 4,316 & 1,547 & .36 & 1,547 & .36 & & & \\
\hline countries) & 2005-2010 & 5,189 & 1,035 & .20 & 922 & .18 & & -5 & 1.1 \\
\hline
\end{tabular}

Benchmark is global average income shortfall in 1992-2000 period: 39.5\$ per day 
Table 2: Person Equivalent Headcount Measures by Region (1990s Global Benchmark)

\begin{tabular}{|c|c|c|c|c|c|c|c|c|c|}
\hline Region & $\begin{array}{c}\text { Range of } \\
\text { Years }\end{array}$ & $\begin{array}{c}\text { Population } \\
\text { n (millions) }\end{array}$ & $\begin{array}{l}\text { Headcount } \\
\text { q (millions) }\end{array}$ & $\begin{array}{c}\text { Headcount } \\
\text { ratio } H\end{array}$ & $\begin{array}{l}\text { Person-equivalent } \\
\text { headcount qe (mill.) }\end{array}$ & $\begin{array}{l}\text { Person-equivalent } \\
\text { headcount ratio } H_{e}\end{array}$ & $\begin{array}{c}\text { \% change } \\
\text { in } \mathrm{H}\end{array}$ & $\begin{array}{c}\text { \% change } \\
\text { in } \mathrm{H}_{\mathrm{e}}\end{array}$ & $\begin{array}{c}\text { Depth } \\
\text { Elasticity }\end{array}$ \\
\hline \multirow{2}{*}{$\begin{array}{l}\text { East Asia \& } \\
\text { Pacific }\end{array}$} & 1992-97 & 1,635 & 615 & .38 & 575 & .35 & \multirow{2}{*}{$-71 \%$} & \multirow{2}{*}{$-79 \%$} & \multirow{2}{*}{1.1} \\
\hline & 2007-10 & 1,842 & 201 & .11 & 134 & .07 & & & \\
\hline \multirow{2}{*}{$\begin{array}{c}\text { Europe \& } \\
\text { Central Asia }\end{array}$} & $1993-2000$ & 399 & 15 & .04 & 12 & .03 & \multirow{2}{*}{$-74 \%$} & \multirow{2}{*}{$-83 \%$} & \multirow{2}{*}{1.1} \\
\hline & $2007-10$ & 402 & 4 & .01 & 2 & .01 & & & \\
\hline \multirow{2}{*}{$\begin{array}{l}\text { Latin America } \\
\text { \& Caribbean }\end{array}$} & 1993-99 & 457 & 43 & .09 & 60 & .13 & \multirow{2}{*}{$-49 \%$} & \multirow{2}{*}{$-48 \%$} & \multirow{2}{*}{0.97} \\
\hline & 2005-10 & 535 & 26 & .05 & 38 & .07 & & & \\
\hline \multirow{2}{*}{$\begin{array}{c}\text { Middle East \& } \\
\text { North Africa }\end{array}$} & $1994-98$ & 179 & 7 & .04 & 4 & .02 & \multirow{2}{*}{$-35 \%$} & \multirow{2}{*}{$-25 \%$} & \multirow{2}{*}{0.73} \\
\hline & 2005-10 & 213 & 5 & .02 & 3 & .02 & & & \\
\hline \multirow{2}{*}{ South Asia } & $1993-96$ & 1,210 & 608 & .50 & 537 & .44 & \multirow{2}{*}{$-37 \%$} & \multirow{2}{*}{$-49 \%$} & \multirow{2}{*}{1.3} \\
\hline & 2007-10 & 1,553 & 489 & .32 & 354 & .23 & & & \\
\hline \multirow{2}{*}{$\begin{array}{c}\text { Sub-Saharan } \\
\text { Africa }\end{array}$} & $1992-2000$ & 441 & 260 & .59 & 359 & .81 & \multirow{2}{*}{$-16 \%$} & \multirow{2}{*}{$-23 \%$} & \multirow{2}{*}{1.4} \\
\hline & 2005-10 & 625 & 308 & .49 & 390 & .62 & & & \\
\hline
\end{tabular}

Benchmark is global average income shortfall in 1992-2000 period: 39.5\$ per day 
Table 3: Person Equivalent Headcount Measures for Selected Countries (1990s Global Benchmark)

\begin{tabular}{|c|c|c|c|c|c|c|c|c|c|}
\hline Country & Year & $\begin{array}{l}\text { Population } \\
\text { n (millions) }\end{array}$ & $\begin{array}{l}\text { Headcount } \\
\text { q (millions) }\end{array}$ & $\begin{array}{l}\text { Headcount } \\
\text { ratio } H\end{array}$ & $\begin{array}{l}\text { Person-equivalent } \\
\text { headcount qe (mill.) }\end{array}$ & $\begin{array}{l}\text { Person-equivalent } \\
\text { headcount ratio } H_{e}\end{array}$ & $\begin{array}{c}\text { Annual \% } \\
\text { change in } \mathbf{H}\end{array}$ & $\begin{array}{c}\text { Annual \% } \\
\text { change in } \mathrm{H}_{\mathrm{e}}\end{array}$ & $\begin{array}{c}\text { Depth } \\
\text { Elasticity }\end{array}$ \\
\hline \multirow{2}{*}{ Bolivia } & 1993 & 7 & 0.6 & .09 & 0.8 & .11 & \multirow{2}{*}{$1.5 \%$} & \multirow{2}{*}{$3.5 \%$} & \multirow{2}{*}{2.3} \\
\hline & 2008 & 10 & 1.0 & .16 & 1.6 & .17 & & & \\
\hline \multirow{2}{*}{ Brazil } & 1995 & 162 & 16 & .110 & 21 & .13 & \multirow{2}{*}{$-3.7 \%$} & \multirow{2}{*}{$-3.0 \%$} & \multirow{2}{*}{0.8} \\
\hline & 2009 & 193 & 9 & .05 & 15 & .08 & & & \\
\hline \multirow{2}{*}{ China } & 1996 & 1,218 & 455 & .37 & 427 & .35 & \multirow{2}{*}{$-5.4 \%$} & \multirow{2}{*}{$-5.8 \%$} & \multirow{2}{*}{1.1} \\
\hline & 2010 & 1,338 & 123 & .09 & 86 & .06 & & & \\
\hline \multirow{2}{*}{ Vietnam } & 1993 & 68 & 44 & .64 & 51 & .74 & \multirow{2}{*}{$-4.8 \%$} & \multirow{2}{*}{$-5.5 \%$} & \multirow{2}{*}{1.1} \\
\hline & 2008 & 85 & 14 & .17 & 10 & .12 & & & \\
\hline \multirow{2}{*}{ India } & 1993 & 921 & 455 & .49 & 395 & .43 & \multirow{2}{*}{$-2.1 \%$} & \multirow{2}{*}{$-2.8 \%$} & \multirow{2}{*}{1.3} \\
\hline & 2009 & 1,190 & 388 & .33 & 282 & .24 & & & \\
\hline \multirow{2}{*}{ Nepal } & 1995 & 21 & 14 & .68 & 17 & .81 & \multirow{2}{*}{$-4.4 \%$} & \multirow{2}{*}{$-5.4 \%$} & \multirow{2}{*}{1.2} \\
\hline & 2010 & 27 & 6 & .24 & 4 & .16 & & & \\
\hline \multirow{2}{*}{ Egypt } & 1995 & 61 & 1.5 & .025 & .66 & .011 & \multirow{2}{*}{$-2.5 \%$} & \multirow{2}{*}{$0.7 \%$} & \multirow{2}{*}{-0.3} \\
\hline & 2008 & 76 & 1.3 & .017 & .88 & .012 & & & \\
\hline \multirow{2}{*}{ Kenya } & 1994 & 27 & 8 & .29 & 8 & .30 & \multirow{2}{*}{$4.6 \%$} & \multirow{2}{*}{$7.1 \%$} & \multirow{2}{*}{1.5} \\
\hline & 2005 & 36 & 16 & .43 & 19 & .54 & & & \\
\hline \multirow{2}{*}{ Mozambique } & 1996 & 16 & 13 & .81 & 21 & 1.3 & & & \\
\hline & 2007 & 23 & 14 & .61 & 19 & .82 & $-2.2 \%$ & $-3.3 \%$ & 1.5 \\
\hline & 1994 & 9 & 7 & .78 & 11 & 1.2 & & & \\
\hline Niger & 2007 & 14 & 6 & .42 & 5 & .37 & $-3.5 \%$ & $-5.3 \%$ & 1.5 \\
\hline So & 1995 & 39 & 8 & .21 & 6 & .17 & $6 \%$ & $-41 \%$ & \\
\hline SoutII AIIICd & 2008 & 50 & 7 & .14 & 4 & .07 & $-2.0 \%$ & $-4.1 \%$ & 1.6 \\
\hline
\end{tabular}

Benchmark is global average income shortfall in 1992-2000 period: $39.5 \$$ per day 
Table 4: Countries in Sub-Saharan Africa (2000s Regional Benchmark)

\begin{tabular}{|c|c|c|c|c|c|c|}
\hline Country & Year & $\begin{array}{l}\text { Population } \\
\text { n (millions) }\end{array}$ & $\begin{array}{l}\text { Headcount q } \\
\text { (millions) }\end{array}$ & $\begin{array}{l}\text { Headcount } \\
\text { ratio } H\end{array}$ & $\begin{array}{c}\text { Person-equivalent } \\
\text { headcount } q_{e} \text { (mill.) }\end{array}$ & $\begin{array}{l}\text { Person-equivalent } \\
\text { headcount ratio } H_{e}\end{array}$ \\
\hline Burkina & 2009 & 15 & 6.7 & .44 & 5.5 & .37 \\
\hline Burundi & 2006 & 8 & 6.5 & .81 & 7.3 & .91 \\
\hline Cameroon & 2007 & 19 & 5.2 & .28 & 3.5 & .18 \\
\hline Central African Republic & 2008 & 4 & 2.6 & .63 & 3.3 & .78 \\
\hline Cote d'Ivoire & 2008 & 18 & 6.4 & .35 & 5.8 & .32 \\
\hline Ethiopia & 2010 & 87 & 34 & .39 & 23 & .26 \\
\hline Ghana & 2005 & 21 & 6.1 & .29 & 5.3 & .25 \\
\hline Guinea & 2007 & 10 & 4.0 & .39 & 3.3 & .33 \\
\hline Kenya & 2005 & 36 & 16 & .43 & 15 & .42 \\
\hline Madagascar & 2010 & 21 & 18 & .88 & 26 & 1.2 \\
\hline Malawi & 2010 & 15 & 10.8 & .72 & 12.9 & .86 \\
\hline Mali & 2010 & 14 & 7.1 & .51 & 5.8 & .41 \\
\hline Mauritania & 2008 & 3.4 & .80 & .23 & .58 & .17 \\
\hline Mozambique & 2007 & 23 & 14 & .61 & 15 & .65 \\
\hline Niger & 2007 & 14 & 6.0 & .42 & 4.2 & .29 \\
\hline Nigeria & 2009 & 155 & 96 & .62 & 107 & .67 \\
\hline Rwanda & 2010 & 11 & 6.8 & .63 & 7.2 & .66 \\
\hline Senegal & 2005 & 11 & 3.8 & .34 & 3.0 & .27 \\
\hline South Africa & 2008 & 50 & 6.8 & .14 & 2.8 & .06 \\
\hline Swaziland & 2009 & 1.2 & .46 & .40 & .45 & .38 \\
\hline Tanzania & 2007 & 41 & 28 & .68 & 29 & .70 \\
\hline Uganda & 2009 & 33 & 12 & .38 & 10 & .30 \\
\hline Zambia & 2010 & 13 & 9.8 & .74 & 14 & 1.0 \\
\hline
\end{tabular}

Benchmark is Sub-Saharan Africa region’s average income shortfall in 2005-2010: 50.0\$ per day 
Table 5: Person Equivalent Headcount Measures in Niger (1994 Country Benchmark)

\begin{tabular}{|ccccccccc|}
\hline Year & $\begin{array}{c}\text { Population } \\
\mathbf{n} \text { (millions) }\end{array}$ & $\begin{array}{c}\text { Headcount } \\
\mathbf{q} \text { (millions) }\end{array}$ & $\begin{array}{c}\text { Headcount } \\
\text { ratio } \mathbf{H}\end{array}$ & $\begin{array}{c}\text { Person-equivalent } \\
\text { headcount } \mathbf{q}_{\mathbf{e}}(\text { mill.) }\end{array}$ & $\begin{array}{c}\text { Person-equivalent } \\
\text { headcount ratio } \mathbf{H}_{\mathbf{e}}\end{array}$ & $\begin{array}{c}\text { Annual \% } \\
\text { change in } \mathbf{H}\end{array}$ & $\begin{array}{c}\text { Annual \% } \\
\text { change in } \mathbf{H}_{\mathbf{e}}\end{array}$ & $\begin{array}{c}\text { Depth } \\
\text { Elasticity }\end{array}$ \\
1994 & 8.9 & 6.9 & .78 & 6.9 & .78 & $-3.5 \%$ & $-5.3 \%$ & 1.5 \\
2007 & 14.2 & 6.0 & .42 & 3.4 & .24 & & & \\
\hline
\end{tabular}

Benchmark is Niger’s average income shortfall in 1994: 61.7థ per day

Table 6: Global Person-Equivalent Poverty including Squared Gaps (1990s Global Benchmark)

\begin{tabular}{|c|c|c|c|c|c|c|c|c|c|c|c|c|c|}
\hline & Years & n (mill.) & q (mill.) & $\mathbf{H}$ & $\mathrm{q}_{\mathrm{e}}$ (mill.) & $\mathbf{H}_{\mathrm{e}}$ & $\mathrm{q}_{\mathrm{e} 2}$ (mill.) & $\mathbf{H}_{\mathbf{e} 2}$ & $\% \Delta H$ & $\% \Delta H_{e}$ & $\% \Delta H_{e 2}$ & $\begin{array}{c}\text { Depth } \\
\text { Elasticity }\end{array}$ & $\begin{array}{c}\text { Severity } \\
\text { Elasticity }\end{array}$ \\
\hline $\begin{array}{l}\text { World (78 } \\
\text { countries) }\end{array}$ & $\begin{array}{l}1992-2000 \\
2005-2010\end{array}$ & $\begin{array}{l}4,321 \\
5,189\end{array}$ & $\begin{array}{l}1,547 \\
1,035\end{array}$ & $\begin{array}{l}.36 \\
.20\end{array}$ & $\begin{array}{c}1,547 \\
922\end{array}$ & $\begin{array}{l}.36 \\
.18\end{array}$ & $\begin{array}{l}1,547 \\
897\end{array}$ & $\begin{array}{l}.36 \\
.17\end{array}$ & $-44.3 \%$ & $-50.4 \%$ & $-51.8 \%$ & 1.1 & 2 \\
\hline
\end{tabular}

Benchmark for $q_{e}$ and $H_{e}$ is global average income shortfall in 1992-2000 period: $39.5 \$$ per day.

Benchmark for $q_{e 2}$ and $H_{e 2}$ is global average squared income shortfall in 1992-2000: $22 \$^{2}$ per day, equivalent to a gap of 47థ per day. 
Table 7: Person Equivalent Poverty among Regions including Squared Gaps (1990s Global Benchmark)

\begin{tabular}{|c|c|c|c|c|c|c|c|c|c|c|c|c|c|}
\hline Region & Years & n (mill.) & q (mill.) & $\mathbf{H}$ & $\mathrm{q}_{\mathrm{e}}$ (mill.) & $\mathbf{H}_{\mathbf{e}}$ & $\begin{array}{c}\mathbf{q}_{\mathrm{e} 2} \\
\text { (mill.) }\end{array}$ & $\mathbf{H}_{\mathbf{e} 2}$ & $\% \Delta \mathbf{H}$ & $\% \Delta \mathbf{H}_{\mathrm{e}}$ & $\% \Delta \mathbf{H}_{\mathrm{e} 2}$ & $\begin{array}{c}\text { Depth } \\
\text { Elasticity }\end{array}$ & $\begin{array}{c}\text { Severity } \\
\text { Elasticity }\end{array}$ \\
\hline \multirow{2}{*}{$\begin{array}{c}\text { East Asia \& } \\
\text { Pacific }\end{array}$} & 1992-97 & 1,635 & 615 & .38 & 575 & .35 & 524 & .32 & \multirow{2}{*}{$-71 \%$} & \multirow{2}{*}{$-79 \%$} & \multirow[b]{2}{*}{$-84 \%$} & \multirow[b]{2}{*}{1.1} & \multirow[b]{2}{*}{1.2} \\
\hline & 2007-10 & 1,842 & 201 & .11 & 134 & .07 & 94.4 & .05 & & & & & \\
\hline \multirow{2}{*}{$\begin{array}{c}\text { Europe \& } \\
\text { Central Asia }\end{array}$} & 1993-2000 & 399 & 15 & .04 & 12 & .03 & 11 & .03 & \multirow{2}{*}{$-74 \%$} & \multirow{2}{*}{$-83 \%$} & \multirow{2}{*}{$-80 \%$} & \multirow{2}{*}{1.1} & \multirow{2}{*}{1.1} \\
\hline & 2007-10 & 402 & 4 & .01 & 2 & .01 & 2.3 & .01 & & & & & \\
\hline \multirow{2}{*}{$\begin{array}{l}\text { Latin America } \\
\text { \& Caribbean }\end{array}$} & 1993-99 & 457 & 43 & .09 & 60 & .13 & 90 & .20 & \multirow[b]{2}{*}{$-49 \%$} & \multirow[b]{2}{*}{$-48 \%$} & \multirow[b]{2}{*}{$-46 \%$} & \multirow[b]{2}{*}{0.97} & \multirow[b]{2}{*}{0.93} \\
\hline & 2005-10 & 535 & 26 & .05 & 38 & .07 & 59 & .11 & & & & & \\
\hline \multirow[b]{2}{*}{$\begin{array}{l}\text { Middle East \& } \\
\text { North Africa }\end{array}$} & 1994-98 & 179 & 7 & .04 & 4 & .02 & 2.8 & .016 & \multirow[b]{2}{*}{$-35 \%$} & \multirow[b]{2}{*}{$-.25 \%$} & \multirow[b]{2}{*}{$-5 \%$} & \multirow[b]{2}{*}{0.73} & \multirow[b]{2}{*}{.14} \\
\hline & 2005-10 & 213 & 5 & .02 & 3 & $\begin{array}{c}2 \\
.01 \\
6\end{array}$ & 3.2 & .015 & & & & & \\
\hline \multirow{2}{*}{ South Asia } & 1993-96 & 1,210 & 608 & .50 & 537 & .44 & 464 & .38 & \multirow{2}{*}{$-37 \%$} & \multirow{2}{*}{$-49 \%$} & \multirow{2}{*}{$-55 \%$} & \multirow{2}{*}{1.3} & \multirow{2}{*}{1.5} \\
\hline & 2007-10 & 1,553 & 489 & .32 & 354 & .23 & 268 & .17 & & & & & \\
\hline \multirow{2}{*}{$\begin{array}{c}\text { Sub-Saharan } \\
\text { Africa }\end{array}$} & 1992-2000 & 441 & 260 & .59 & 359 & .81 & 456 & 1.0 & \multirow{2}{*}{$-16 \%$} & \multirow{2}{*}{$-23 \%$} & \multirow{2}{*}{$-27 \%$} & \multirow{2}{*}{1.4} & \multirow{2}{*}{1.7} \\
\hline & 2005-10 & 625 & 308 & .49 & 390 & .62 & 471 & .75 & & & & & \\
\hline
\end{tabular}

Benchmark for $q_{e}$ and $H_{e}$ is global average income shortfall in 1992-2000 period: 39.5థ per day.

Benchmark for $q_{e 2}$ and $H_{e 2}$ is global average squared income shortfall in 1992-2000: $22 \$^{2}$ per day, equivalent to a gap of $47 \pitchfork$ per day. 
Figure 1: Regional Headcounts 1992-2000
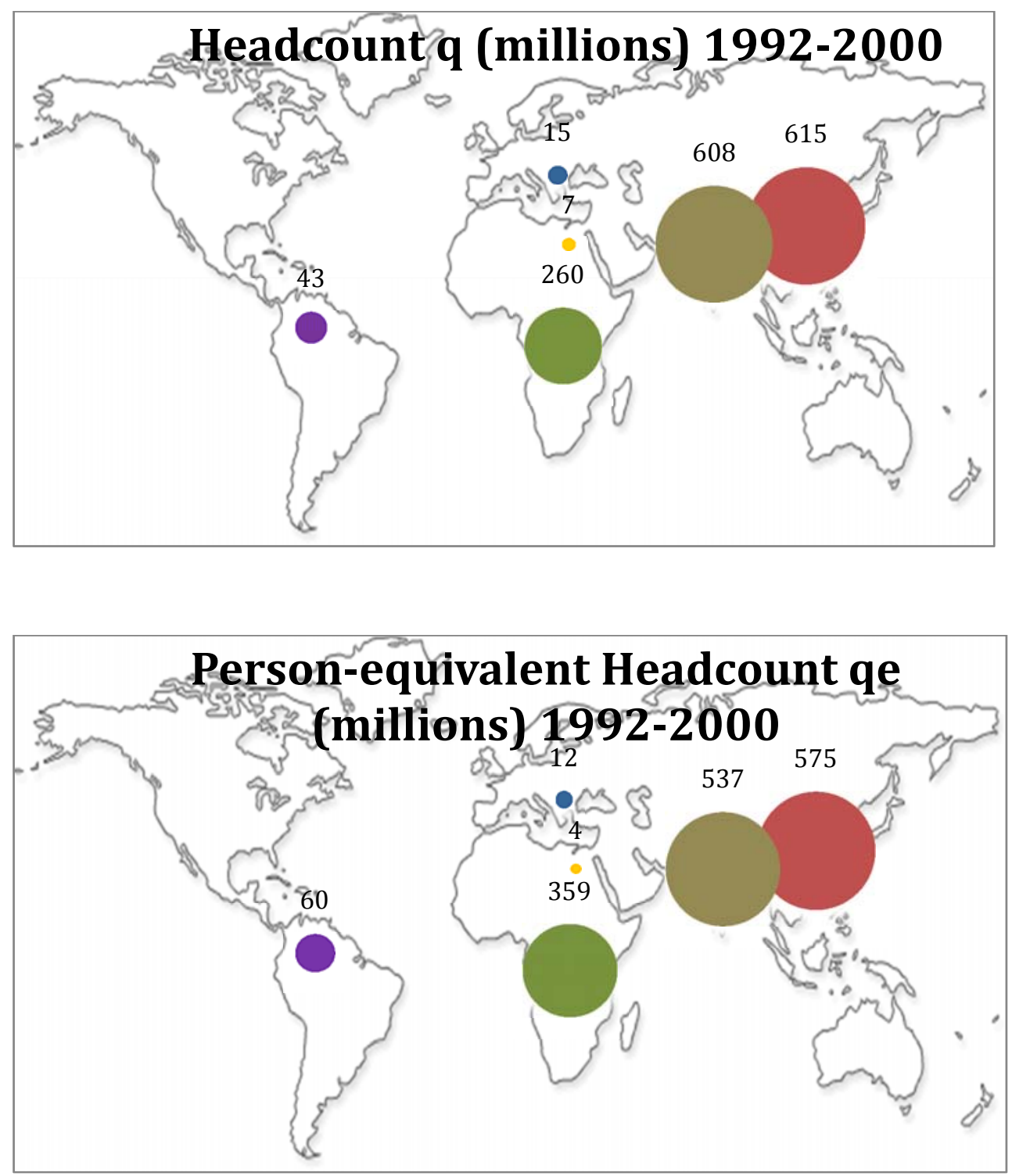
Figure 2: Regional Headcounts 2005-2010
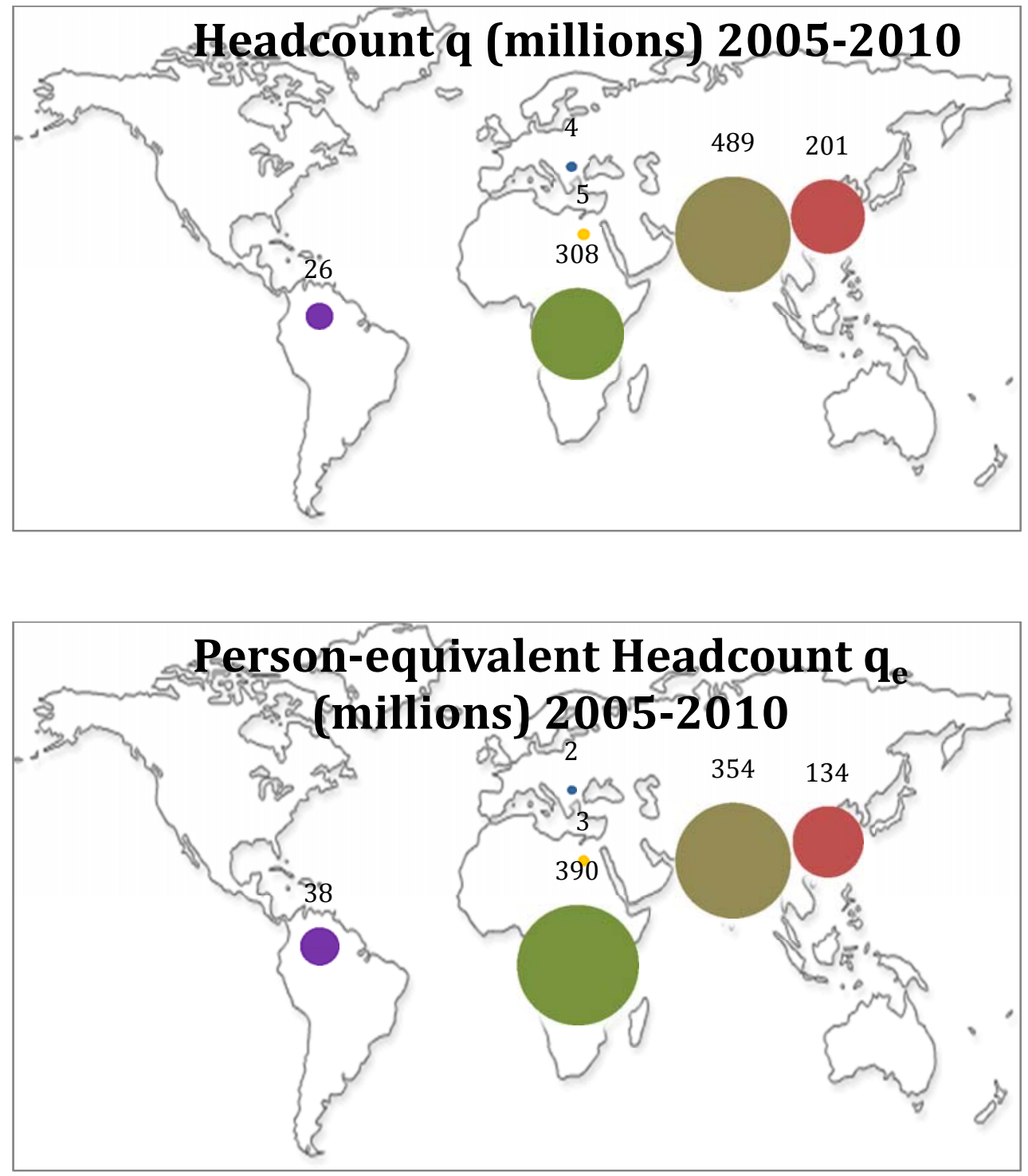


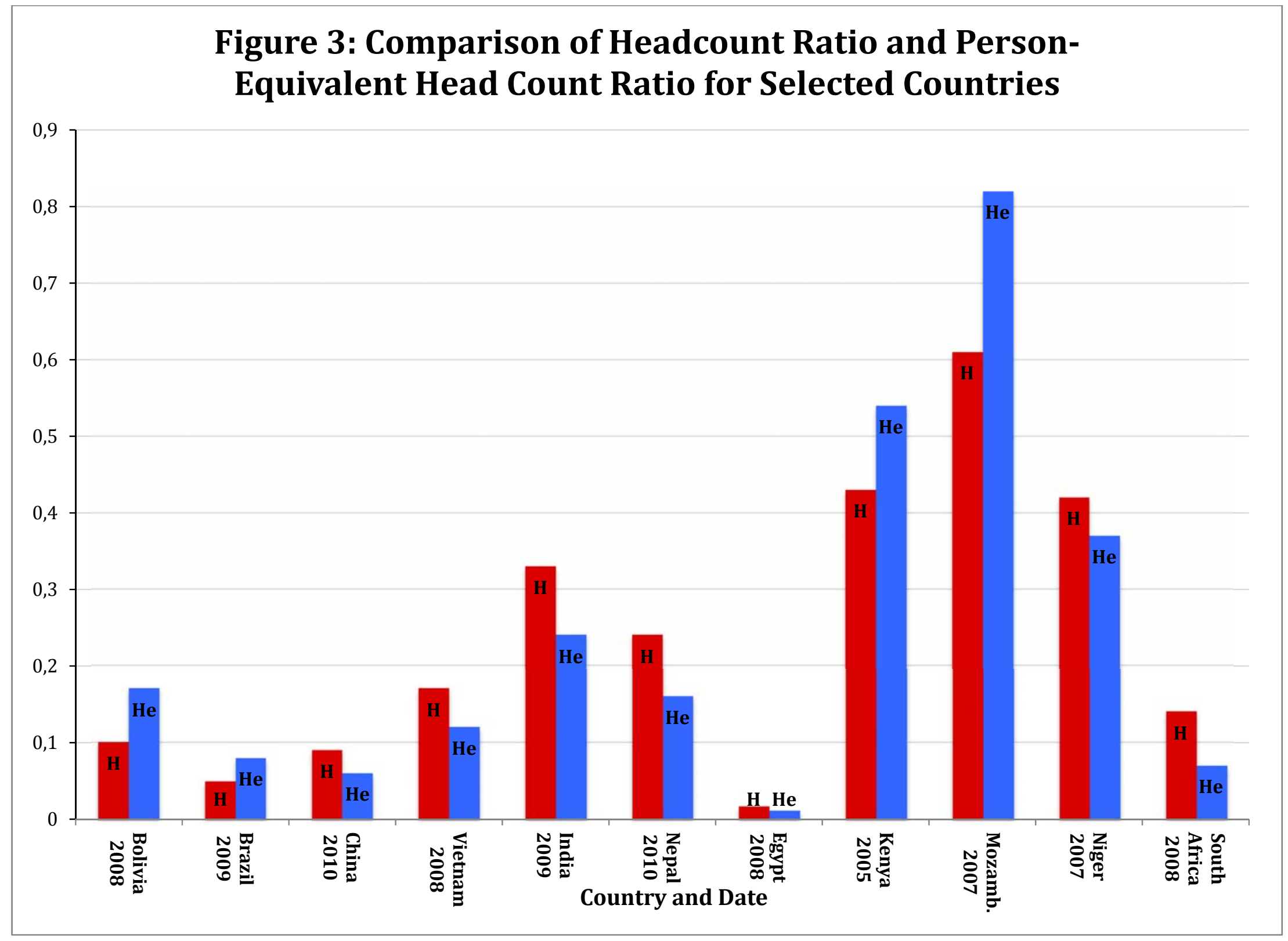




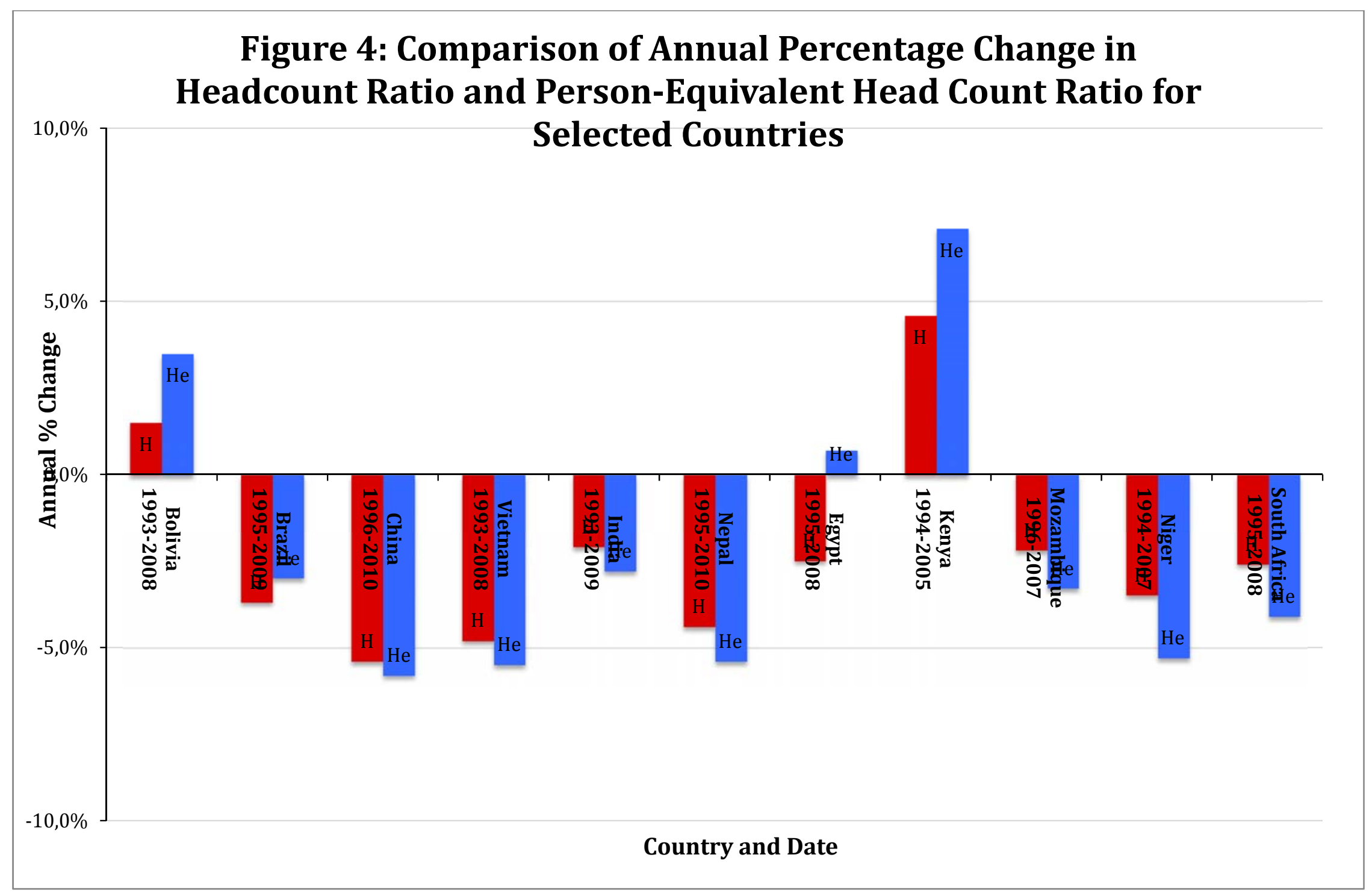

